
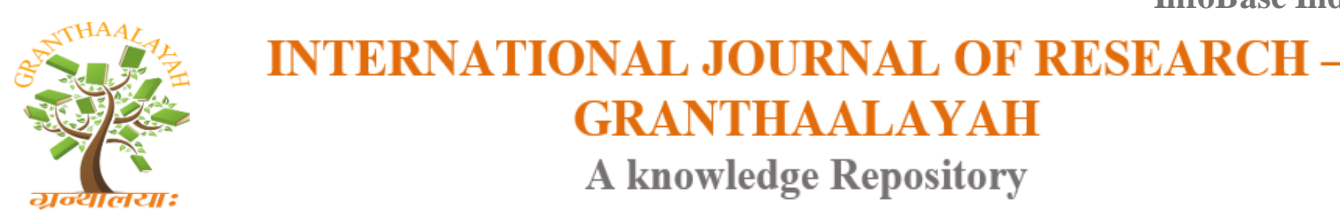

Management

\title{
WEALTH MANAGEMENT THROUGH ROBO ADVISORY
}

\author{
Ishmeet Singh ${ }^{1}$, Navjot Kaur ${ }^{2}$ \\ ${ }^{1}$ Assistant Professor, Sri Guru Nanak Dev Khalsa College, D B Gupta Road, Dev Nagar, New \\ Delhi 110005, India \\ ${ }^{2}$ Assistant Professor, Sri Guru Tegh Bahadur Khalsa College, North Campus, University of \\ Delhi, Delhi 110007, India
}

DOI: https://doi.org/10.29121/granthaalayah.v5.i6.2017.1991

\begin{abstract}
Use of artificial intelligence is changing the working styles of human beings in almost every sphere. From Travel, health, education, communication and other related fields, it has now entered wealth management. A number of wealth management firms have adopted the artificial intelligence based services to the clients so that they are able to get investment advice any time as per their convenience. These services are quickly accessible, cheaper, transparent and unbiased. Since the advisory services are being provided by the machines just like robots, they have been called "robo - advisors".

This study is focussed on evolution of robo advisory model, its needs and potential in wealth management. The information gathered for this paper is based on the secondary data collected from various newspapers, magazines, journals and reports.

At present the use of robo - advisors is quite small but it does have a bright future. Though a bit expensive at the initial stage, they prove to be cost effective later as they save the cost of human advisors. It also offers good decision making since it is based on systematic and quantitative research. This paper tries to highlight the potential of robo advisors in wealth management and also discusses its present status and future prospects.
\end{abstract}

Keywords: Wealth Management; Robo-Advisors; Asset Allocation.

Cite This Article: Ishmeet Singh, and Navjot Kaur. (2017). "WEALTH MANAGEMENT THROUGH ROBO ADVISORY." International Journal of Research - Granthaalayah, 5(6), 33-43. https://doi.org/10.29121/granthaalayah.v5.i6.2017.1991.

\section{Introduction}

Machine intelligence or artificial intelligence has touched almost every field of human life. It is being extensively used to assist human beings in almost all the fields like business, jobs, health, education etc. In the field of finance also, we are shifting from conventional techniques that involve large scale use of paper (documents and files) and repeating the process of taking similar 
decisions for a large number of people in a mechanical way. We have used machines programmed efficiently to do the most of our mechanical work. Now we have started using the machines programmed in such a way that they are able to scrutinise given information, analyse the information and offer intelligent solutions just like human advisors. These machine advisors are called robo-advisors. A number of wealth management companies have already started robo advisory services and the results are also quite encouraging. Some of them are following the hybrid robo advisory services in which human advisors also have a complementary role.

\subsection{Literature Survey}

The concept of savings and investment is changing with time. People are slowly moving towards online investments in mutual funds, equities etc. which provides the automatic selection of assets which fulfils the requirement of an individual and also gives the maximum benefits. "A roboadvisor (robo-adviser) is an online service dealing with wealth management. It provides automated, algorithm-based portfolio management advice without the use of human financial planners.

Robo advisor is an automated advisory system or online portal where robo advice is based around algorithm trading. You can get online investment services and can easily manage your portfolio without much of human intervention.

F.Dapp (2016) discusses about the working and advantages of using robo advisors. Artificial intelligence has taken place in all areas of our lives. A lot of progress has been made in the field of pattern recognition, modern data analysis and the use of self-learning algorithms. To handle an exponential growth in data volumes, we need corresponding progress in the field of technology. That means we need professional digital services to manage financial data, provide intelligent advisory solutions to the investors and be prepared to cope with the data potential that will provide challenges in future.

A Joint Committee Discussion Paper on automation in financial advice by Joint Committee of the European Supervisory Authorities (December 2015) has described continued increase in the digitalization of financial services across the banking, insurance and securities sectors. The main characteristics of automated financial advice tools have been discussed in terms of potential benefits and potential risks and limitations or errors in automated tools that may not be easily identifiable for consumers or financial institutions. The committee feels that in the securities sector, automation of financial advice is a more mature phenomenon. The automated financial advice tools use a website where an investor (or potential investor) uses an online questionnaire to enter information about his or her specific circumstances. This includes the investor's risk appetite; investment goals; and facts relating to the investor's life and situation. On the basis of the information collected, the tool generates recommended transactions suitable for the investor. Jonathan Walter Lam in his book 'Robo-Advisors: A Portfolio Management Perspective' discusses how robo advisors work on asset allocation with mean-variance analysis, use exchange-traded funds to represent each asset class, focusing on how ETFs contribute to net-of fee, after-tax, risk-adjusted portfolio returns and employ threshold-based rebalancing to maintain investment discipline. He compares different robo advisors available and also discusses how they are different from traditional advisors. 
Robo-Advisory Services Study (2015) by A.T. Kearney (a leading global management consulting firm) was conducted on a nationally representative sample of more than 4,000 U.S. consumers who were at least 18 years of age at the time of study and who had bank accounts. The study focussed on consumers' investment decision making, awareness of, interest in, and willingness to use robo-advisory services. The study concluded that robo-advisory will grow at a fast pace as more and more people find working on digital platforms easier than going to an investment advisor physically. They found that the growth of the robo-advisors will erode overall asset management revenue. The traditional players will have to lower their fees structure and this will result in loss in billions of dollars. They classified the investors as pioneers, enthusiasts, potential late adopters and unlikely adopters. The study showed that only a small percentage of people fall in the last two categories. They concluded that future of robo advisory is very bright and people will invest more than 2.2 trillion dollars by 2020 through robo advisors.

A study by Infosys named 'Robo-advisor - automation to enhance financial advisory' has found that in USA, from being $0.2 \%$ fee based advisory AUM of traditional players in 2014, robo advisors are expected to grow up to $17 \%$ within six years with a compound annual growth rate (CAGR) of $120 \%$. They suggested that a hybrid robo-advisor (that takes the services of human beings as well) will perform better than the robo-advisor. They felt that no tool ever can kill the need of a good human financial advisor.

Accenture's report 'The Rise of Robo-Advice - Changing the Concept of Wealth Management' says that although robo-advice has gained only a small share of assets under management (AUM), it presents investors with an interesting value proposition - with a price reduction of as much as 70 percent for some services - and its rate of growth is both rapid and accelerating. "Digital" wealth-management assets, including those at traditional firms, are projected to reach between $\$ 55$ billion and $\$ 60$ billion by the end of 2015 .

The conclusion of Accenture report is "Despite the quick uptake of robo-advice services among wealth management firms and individual investors, their share of assets under management is quite small. The lower price for robo-advice services is likely to put pressure on the market price for many services. Robo-advice will also give wealth management firms access to a large new market of millennials who are interested in accumulating wealth, but have had only limited options in terms of investment management. Finally, advances in technology- particularly in cognitive computing and "smart machines" capable of complex reasoning and interaction with humans-will transform the investing landscape in potentially disruptive ways. For wealth management firms, robo-advice services can be a bet on the future - a way to get customers and financial advisors acclimated to working with machines that can enhance and extend human performance."

BlackRock's 'Digital Investment Advice' : Robo Advisors Come of Age' studies about Digital advisory services and concludes that they have the potential to significantly mitigate behavioural finance biases and provide customized investment tools to individual investors at a relatively low cost. They feel that as policy makers, they should consider the rapidly evolving digital advice landscape and the application of existing regulations to digital advisors. It is also important to allow for a variety of different digital advice business models that meet different client needs, including both start-up firms and existing market players such as established wealth managers 
with direct-to-consumer platforms or business-to-business platforms. In thinking about where to focus attention in the digital advisory space, the five specific areas need consideration: (i) disclosure standards and cost transparency, (ii) know your client and suitability requirements, (iii) algorithm design and oversight, (iv) trading practices, and (v) data protection and cyber security.

(Park1 et al.) examined US asset management firms that use robo-advisors to manage assets and investigated the robo-advisor strategies of the top companies, namely Schwab Intelligent, Wealth front, and Betterment. They found that their investment philosophies for robo-advisors are similar, but each robo-advisor uses different approaches in its process of selecting asset types and assets to invest in.

'The Future of Advisory: Exploring the Impact of Robo on Wealth Management - A Finextra White Paper produced in association with EPAM (September 2016) states that the impact of robo on traditional wealth advisory is unlikely to be very disruptive.

The purpose of the report has been to assess the progress of robo advisory, to explore the likely ways in which digital will continue to impact the wealth management industry going forward, and to determine the future of advisory in light of the evolution of technology and its continued adoption by new and established players. The robo advisors themselves are also concerned about risks because, if something went wrong, they would all get tarred.

Market Research Centre, PWC found "Robo-advisors" services have become increasingly popular in the last few years, with Wealthfront and Betterment leading the way in the US and Nutmeg in the UK. On a global basis, robo-advisors directly managed about USD 19 billion as on December 2014, according to a study by Corporate Insight. This figure is set to grow since virtual advisors are providing personalized portfolio allocation, tax aware portfolio design, and smart rebalancing to maintain a target risk and 24/7 access with lower fees than other types of advisors.

\section{Wealth Management}

Wealth managements involves three basic functions -

1) Wealth Development by setting goals and investing accordingly. The financial advisor educates the client and follows an approach based on diversification, asset allocation keeping in mind clients' goals and interests.

2) Wealth Protection through a careful portfolio management that avoids risks (risk management), asset allocation that helps to meet client's needs, providing protection from unforeseen events (illness, disability etc.), rebalancing portfolio on regular basis to maintain stability and confidence of the client.

3) Tax minimization strategies that help in efficient tax planning and minimizing tax losses.

\section{Asset Allocation}

Asset allocation is a major part of financial planning. It is the implementation of an investment strategy that attempts to balance risk versus reward. For this purpose, it adjusts the percentage of 
each asset in an investment portfolio on the basis of investor's risk tolerance, goals and investment time frame. For example, it distributes investor 'A's investments among various types of available options like stocks, bonds, equities, mutual funds etc. to get maximum output from it. While doing so, it will consider factors related to the investor like his age, income, marital status and the risk bearing capability.

\subsection{Asset Allocation and Diversification}

The principal reason for diversifying investments across different asset classes is to minimize the risk of a portfolio. It requires one to avoid investments whose returns tend to move too closely with each other. So if one was to invest in growth stocks, value stocks, small caps and midcaps it would mean that their returns would be highly correlated so they would virtually fall in the same asset class. However, in case of fixed income instruments there are different varieties of instruments available which would depend on the tenor, issuer, credit rating and the cash flows. It would also depend on the nature of the instrument, for example, convertible and nonconvertible, fixed rate or flexible rate, listed or unlisted, marketable and non-marketable and so on.

- Some of the various types of asset classes with their sub - categories are:

- Bonds: government or corporate; short term, intermediate, long term; domestic, foreign, emerging markets, investment grade or high yield.

- Stocks: large cap and small cap; domestic, foreign, value or growth; emerging markets.

- Mutual Funds

- Real estate

- Foreign currency, etc.

Once an individual has identified these asset classes, he needs to know how to divide his/her investments in these asset classes. The key considerations in choosing the asset classes are the level of return and risk. Liquidity, transaction costs and ease of investment are other considerations.

\subsection{Factors to be considered while Asset Allocation}

The factors that one should consider in choosing exposures to different asset classes are as follows:

- Risk Tolerance: The degree to which one can tolerate risk varies for different people and depends on the following:

- Stage in life: A younger person, having a safe livelihood and few dependents, has time on his/her side can take more risk while choosing a portfolio.

- Net Worth: If one owns lot of assets and has few liabilities can take more risk

- Experience with investments: If one has prior experience in investing in financial markets and one is comfortable with short term fluctuations then one can take more risks and hence more exposure to equity.

- Investment Objective: Investment objective is the purpose for which the investments are being made. These objectives could be: 
A person nearing his retirement would want a regular stream of income from the investment, while preserving the capital value, and should hence choose a safer portfolio.

$>$ If one is looking at growth along with preservation of capital, and is investing for a goal that is very important, such as saving for one's child's education, then one can take some more risk in pursuit of higher returns, but not at such a high risk that it might erode one's capital.

$>$ If one is looking at high growth and investing for a goal that is not very important, one can afford to take more risk.

- Time Horizon: The time for which one would like to hold an investment also impacts the level of risk that one can undertake. If the goal for which the investment is being made is occurring after a long time, then one can pursue higher returns by investing in a more risky portfolio as over the period of time the risk reduces.

\subsection{Asset Allocation Models}

There are mainly four asset allocation models:

- Preservation of Capital Model: This asset allocation model is for those who want to preserve their money for near future. The major part of their portfolios includes treasury notes and commercial papers.

- Income Model: This asset allocation model is for those who demand steady income for a considerable period of time, especially those on retirements. Includes investing in real estate, government bonds, and shares of companies with prolonged dividend payments, insurance policies, etc.

- Growth Model: This asset allocation model is for those who want to maximize their capital in a short time. Includes investing mainly in stocks and similar instruments. They mainly follow growth investing strategies and prefer mid and small cap stocks.

- Balanced Model: This asset allocation model is for those who want growth and income. Includes investments in fixed income instruments, real estate, stocks of all sizes (large, mid and small cap in a managed way).

Once an individual has decided on his asset allocation, the next step is which securities within those asset classes should one select, and whether one should change the allocation from time to time based on market conditions.

\subsection{Dynamic Asset Allocation}

Dynamic asset allocation is a strategy that involves rebalancing allocation of fund daily, monthly or quarterly, depending on the mandate of the fund. Such rebalancing would generally involve reducing positions in the best performing asset class, while adding to positions in underperforming assets. It keeps emotions aside and follows a 'Buy Low and Sell High' strategy. This strategy helps to invest in equities when the markets are cheap and book profits when markets rise. 


\section{Wealth Management through Robo - Advisor}

This implies managing client's wealth through on-line process using artificial intelligence through a 'robo advisor'.

\subsection{Robo-Advisor - Meaning}

Robo Advisor is an algorithm driven software that provides automated financial planning services on digital platform. It is designed to perform all the functions like registration, analysis of clients' needs and goals, offer advice, asset allocations, rebalancing etc. It may or may not be assisted by a human advisor.

\subsection{The Evolution of Robo Advisory Model}

The first robo-advisors came alive in 2008. It was first launched by 'Betterment' a wealth management company in US. This innovative program was investor friendly that worked on 'online interface'. The objective was to 'rebalance investor assets within target-date funds'. Rebalancing of the fund is done to make it more conservative as the target date (e.g. the retirement age) approaches with fewer equities and more fixed income.

The strategy followed by robo advisors is essentially passive, 'buy and hold' (investor buys stocks and holds them for a long period of time, regardless of fluctuations in the market). Rebalancing is done only when due to market shifts there is a skew in a portfolio's allocations (equity, debt and other assets).

Prior to this, 'wealth management software' was used by human financial advisors to automate their workload. With Robo advisors, the services of these financial advisors are no more required as the product is directly delivered to clients through digital platform.

\subsection{Different Modes of Robo Advisory}

Auto-pilot: This mode is for new investors to get a start. Some basic packages are given and investment is initiated according to one's need. Scripbox is an example of this mode. It is an online MF investment service firm that offers three 'boxes'-equity, fixed income and taxsaving. It recommends a total of eight funds - four equity funds, two fixed income funds and two tax-saving funds, split into the three different boxes.

Direct plan-based: This mode tries to do away with biased advices, hidden fees, and commissions. It involves minimum advisory and very less fee attached to one's transactions. It is used by companies such as Bharosaclub.com, Orowealth.com and Invezta.com.

Goal-based advisory: In this mode the investor is allowed to enter his/her information and then it provides basic advisory service to help them achieve their long term investment goals. Besides advisory service it allows transactions in shares, company deposits and corporate bonds. BigDecisions.com is an example of such robo advisory platform which answers the initial questions of investors, but doesn't offer products.

Full-service: This mode tends to provide complete advisory service by collecting full information from the investor in the form of a detailed questionnaire filled in by the investor. On 
the basis of the information given in the questionnaire, it assesses the risk appetite, financial goals, saving and spending pattern and current asset liability position of the investor. It also assesses how the investor is managing the monthly liquidity, whether his/her spending is more than earning, what is his/her net worth, whether he/she has enough surplus, taxation and so on. On the basis of the information collected, it gives in-depth advice and offers a full service roboadvisory.

\subsection{Need and Advantages of Robo Advisory}

When it comes to investment and saving many of us are not able to do this due to lack of time, lack of knowledge about different funds and various techniques of investing. There are many issues in the traditional technique of financial management which are overcome by robo advisors. The following factors justify why any investment advisory firm would like to go for a robo advisor -

- Robo advisors can work continuously. So the investment firms provide 24/7 Robo advisors are much cheaper than the traditional advisors. So, they provide low cost services without any human intervention.

- Robo-advisors charge much less than the traditional advisors. For around 1\% plus charges for human advisors, robo advisors charge around $0.15 \%$ to $0.75 \%$ of assets under management.

- Robo investment advisors maintain transparency in the services provided by them like fees, trades \& portfolios, etc.

- Robo-advisors are based on complex, algorithms and assumptions. They use the information given by the investor in an unbiased manner and provide a standardized, diversified portfolio based on an individuals' basic risk tolerance. There are little chances of errors and overall portfolio risks.

- Robo advisors are efficient i.e. every little change in the portfolio can be instructed efficiently \& effectively.

- Robo Advisers can target a large population of small investors who are used to digital working platforms and are the potential wealthy clients of the future.

\subsection{Accessibility to Investors through Robo Financial Advisors}

\section{Available robo advisors in India:}

Many financial firms are now moving towards the online investment and savings. Some of the developed robo advisors in India are:

i. Bigdecisions: It provides online services for all your investment needs.

ii. Fundsindia: It was initially developed for mutual funds only. It was started in 2009 at Chennai. Now it provides financial advice in all the fields of wealth management.

iii. Arthayantra: It is another online service provider which focuses on three main things that are comprehensive financial planning, interconnect different aspects of financial management and make investor's goal centric.

iv. Scripbox: This is also an online platform where investments can be started with a very minimum amount and also guides about the wealth management.

v. MyUniverse ZIPSIP: This is the latest robo advisory firm launched by Aditya birla group. This model focuses on financial management and investment techniques. 


\section{Limitations of using Robo Advisors}

Robo advisors are modern, easy to use and provide standardised investment solutions. But they are not fool proof. They have a number of limitations like -

- They fail to provide a personal guidance. They work on artificial intelligence to the level they are programmed. They can't think beyond their programmed capacity and are not flexible to accommodate a unique situation for which they have not being prepared. They can't provide a 'friendly advice' that many confused people seek desperately especially when the markets are volatile.

- There are times when investors need advice beyond money matters. Or they may require an integration of financial, tax and estate plans. These demands can only be handled by a seasoned human advisor and not a robo advisor.

- Some investors require a face to face meeting with the advisor which is not possible in case of a robo advisor.

- For any change in investment rules or policies, robo advisors need to be reprogrammed and that may take time, money and efforts. Human advisors on the other hand start using the modifications with immediate effect.

\section{Conclusion}

Services of robo-advisors are being opted by a number of companies and this will lead to further testing and improvements. Robo-advisors may not be appropriate for everyone but they definitely offer a valuable complementary resource to investors.

Almost all the Robo Advisory models in India develop a Static Asset Allocation model based on the information given by the investor. They recommend the good funds to invest in. What they miss out is timing the market. They fail to recommend the time when to reduce or increase the weightage in Equity / Debt. There is vacuum for a Dynamic Asset Allocation model which studies the valuation of the market on the basis of the parameters which affect the markets.

\section{References}

[1] Beyer, C. (2017). Evolution and Disruption in the Wealth Management Industry. The Journal of Wealth Management, 19(4), 8-13.

[2] Blanc-Brude, F. The need to inform asset allocation decisions and to adapt regulation.

[3] Chen, H., Ju, N., \& Miao, J. (2014). Dynamic asset allocation with ambiguous return predictability. Review of Economic Dynamics, 17(4), 799-823.

[4] Cocca, T. (2016). Potential and Limitations of Virtual Advice in Wealth Management. Journal of Financial Transformation, 44, 45-57.

[5] Condie, S., Ganguli, J. V., \& Illeditsch, P. K. (2015). Information Inertia.

[6] Deutsche Bank: Robo advice - when machines manage your ... (n.d.). Retrieved March 14, 2017 , from http://www.bing.com

[7] Faber, M. T. (2007). A Quantitative Approach to Tactical Asset Allocation. The Journal of Wealth Management, 9(4), 69-79. doi:10.3905/jwm.2007.674809

[8] Goltz, F. (2010). The global financial crisis has shifted the attention of all investors to risk. A survey of the practices of European pension funds conducted by EDHEC-Risk Institute highlights three great challenges - gaining additional access to performance through optimal diversification, 
improving the hedge of the stream of liabilities, and respecting the minimum funding ratio constraint by insuring downside risk away. Risk Management.

[9] Gupta, A., \& Li, L. (2004). A modeling framework for optimal long-term care insurance purchase decisions in retirement planning. Health Care Management Science, 7(2), 105-117.

[10] Harman, A., van der Lende, E., Somaia, K., \& Kocourek, P. (2014). Dynamic Asset Allocation. Colonial First State Global Asset Management Multi-Asset Solutions Research Papers no, 7.

[11] Hasana, M. S., Ebrahima, Z., Hasrulnizzam, W., Mahmoodb, W., \& Ab Rahmanc, M. N. DECISION SUPPORT SYSTEM CLASSIFICATION AND ITS APPLICATION IN MANUFACTURING SECTOR: AReview.

[12] How Using A Robo Advisor Will Make Your Portfolio More ... (n.d.). Retrieved March 14, 2017 , from https://www.bing.com

[13] Horan, S. M. The future of wealth management: Unpicking where the puck is going.

[14] Koijen, R. S., \& Van Nieuwerburgh, S. (2011). Predictability of returns and cash flows. Annu. Rev. Financ. Econ., 3(1), 467-491.

[15] Lacasse, R. M., Lambert, B. A., Roy, N., Sylvain, J., \& Nadeau, F. (2016). A Digital Tsunami: FinTech and Crowdfunding. In International Scientific Conference on Digital Intelligence. April (pp. 4-6).

[16] Labe, R., \& Oh, J. (2000). U.S. Patent Application No. 09/741,561.

[17] Lynch, D. S. (2015). Asset Allocation Technique for a Diversified Investment Portfolio Using Artificial Neural Networks (Doctoral dissertation, Ohio University).

[18] Meinert, M. C. (2017). Of Investments and Algorithms. American Bankers Association. ABA Banking Journal, 109(1), 30.

[19] Muralidhar, A., Shin, S. H., \& Ohashi, K. (2015). The Most Basic Missing Instrument in Financial Markets: The Case for Forward Starting Bonds.

[20] Musto, C., Semeraro, G., de Gemmis, M., \& Lops, P. (2015). A framework for personalized wealth management exploiting case-based recommender systems. Intelligenza Artificiale, 9(1), 89-103.

[21] Park, J. Y., Ryu, J. P., \& Shin, H. J. (2016). Robo-Advisors for Portfolio Management.

[22] Parasuraman, R., Barnes, M., Cosenzo, K., \& Mulgund, S. (2007). Adaptive automation for human-robot teaming in future command and control systems. Army Research Lab Aberdeen Proving Ground MD Human Research and Engineering Directorate.

[23] Philippon, T. (2016). The FinTech Opportunity (No. w22476). National Bureau of Economic Research.

[24] Reher, M., \& Sun, C. (2016). Robo Advisers and Mutual Fund Stickiness.

[25] Robo Advisors in India - Investing made easy! (2017, February 10). Retrieved February 25, 2017, from http://fintrakk.com/robo-advisors-in-india-investing-made-easy/

[26] Robo-advisor - automation to enhance financial advisory (n.d.). Retrieved March 1, 2017, from https://www.infosys.com

[27] Rukungu, J. M. N. (2015). The impact of new capital gains tax on asset allocation of investment groups in Nairobi (Doctoral dissertation, University of Nairobi).

[28] Scardovi, C. (2016). Fin Tech Innovation and the Disruption of the Global Financial System. In Restructuring and Innovation in Banking (pp. 21-49). Springer International Publishing.

[29] Scherer, B. (2017). Algorithmic portfolio choice: lessons from panel survey data. Financial Markets and Portfolio Management, 31(1), 49-67.

[30] Scherer, B. (2016). What Investment Robots Need To Know-Evidence from Panel Survey Data.

[31] Scheurle, S. (2016). Can Robo-Advice Spur Stock Market Participation? Browser Download This Paper.

[32] Sironi, P. (2016). FinTech Innovation: From Robo-advisors to Goal-based Investing and Gamification. John Wiley \& Sons Limited.

[33] Traff, J. D. (2016). The future of the wealth management industry: evolution or revolution? (Doctoral dissertation, Massachusetts Institute of Technology). 
[34] Tsai, J. (2011). Dynamic asset allocation with learning.

[35] Walter, I. (2015). The Industrial Organization of the Global Asset Management Business. Research Foundation Publications, 2015(5), 1-95.

[36] Werner, J., \& Sjöberg, J. (2016). Prospect Theory in the Automated Advisory Process.

[37] www.blackrock.com(n.d) Retrieved January 2, 2017,from http://www.blavkrock.com

[38] www.fundsindia.com (n.d) Retrieved March 12,2017, from http://www.fundsindia.com

[39] www.scripbox.com (n.d) Retrieved March 12, 2017,from http://www.scripbox.com

*Corresponding author.

E-mail address: ishmeet@gmail.com 